\title{
SUSTAINABLE PORT DEVELOPMENT BASED ON THE BLUE ECONOMY FRAMEWORK IN CHINA: THE EXAMPLE OF QINGDAO PORT
}

\author{
YAN ZHANG ${ }^{1,2} \&$ WIM RAVESTEIJN ${ }^{2}$ \\ ${ }^{1}$ School of Management, Harbin Normal University, China \\ ${ }^{2}$ Faculty of Technology, Policy and Management, Delft University of Technology, The Netherlands
}

\begin{abstract}
This research is focusing on China's new concept of "blue economy" and the integration of it into the country's sustainable development efforts. Under the Blue Economy framework, Chinese ocean-based economic development has experienced an obvious acceleration over the last three decades, which has increased sustainable development capabilities. Meanwhile, national plans are being implemented in order to promote future oceanic sustainable development. The Qingdao Port is the iconic example of the Blue Economy practices resulting from the Chinese oceanic development strategy and it has indeed been quite successful in its development until now since the introduction of the Blue Economic Zone and the Belt and Road Initiative (BRI) programmes. Moreover, the sustainable experience of the Qingdao port shows an optional reference of the blue economic plan to other ports expecting an optimal ocean development. Finally, some challenges and opportunities will be discussed for further research and practical improvements.
\end{abstract}

Keywords: blue economy, BRI, sustainable development, Qingdao port, ocean economy.

\section{INTRODUCTION}

It is widely known that the ocean can be seen as the mother of all mankind since it contains and supports valuable food, resources and livelihood for the global population [1]. The sustainability of oceans has always been related to human survival and development. For the purpose of a better protection of the oceans, the concept of "blue economy" has been introduced in China in order to promote the extension of sustainable development from the land to the oceans. Also, the proposition and idea of the Blue Economy provide an ideal and framework to pursue a better understanding of ocean industrial development, ocean exploitation and usage, healthy ocean ecosystems as well as an upgrade and integration of the ocean port.

With regard to the importance of ocean development, China has been paying much attention to the ocean industry and culture, although it experienced a long-term closed-door policy resulting in a neglect of the ocean and national downfall. Since the building of the People's Republic of China (1949) to the reform and opening up policy (1978), China has grown up from ocean sovereignty to a big ocean nation during the past almost 70 years. Aiming to the nation's "stronger ocean dream", the ideal and practice of the Blue Economy was officially adopted as a key national strategy [2], since the "Development Plan of the Blue Economic Zone" in Shandong, Zhejiang and Guangdong Provinces in 2011, to promote the regional economy and the coordinated development between land and ocean [3]. In order to enhance blue competition and international cooperation, the 21 st Century Maritime Silk Road, similar to the Silk Road Economic Belt in the Belt and Road Initiative (BRI), was proposed to map out the new dream for ocean strength since 2013 [4], [5].

Originally, the Blue Economy programme was designed separately from the BRI, but lately both governmental programmes have been integrated, recently appearing in the official document the "Vision for Maritime Cooperation under the Belt and Road Initiative" in 
2017 [5]. The Chinese government is pursuing a policy line of a sustainable ocean development through the Blue Economy [6]. Consequently, China is not only looking at the ocean as a means of transportation, but also as a rich source of further development.

In view of the Blue Economy, using innovative methods is important for generating more benefits to livelihood [7]. At the same time, protecting the quality of the oceanic sources has been recognized as a significant aspect [8]. In addition, most activities related to marine protection are resulting from port development [9]. Thus, the Blue Economy should ultimately be based on the sustainability of port governance and integration. Under this logic and framework, sustainable port development should be consistent with the Blue Economy [8].

Qingdao, the capital of Shandong Province of China, as a main port between East Asia and the European Union (UN), is considered a focus port in the Blue Economy initiative. After the plan of "Blue Shandong Peninsula Economic Zone" in 2011 [10], Qingdao became the first Blue Economy model. Consequently, Qingdao port has been upgraded to a major strategic pivot for the national strong ocean dream. Also, Qingdao sustainable port development has brought the ocean power together, constituting a potential blueprint for international cooperation in blue growth. It seems that Qingdao has taken the lead of the Blue Economy, not only around the Shandong Bay, but also in China.

In order to deal with these issues, in this paper, we focus on sustainable port development within the Blue Economy framework along the new Silk Road. Two questions can be formulated for this contribution: (1) how are sustainable development and the Blue Economy related? (2) How can sustainable development be promoted through the Blue Economy and the other way around?

These questions will be dealt with focussing on the port of Qingdao. After this introduction, in the second section, the concepts of sustainable development and blue economy will be analysed showing and discussing the connection. An overview of Chinese sustainable port development will be provided in the third section. Consequently, we will illustrate our argument with sustainable development under the blue economy framework in the case of Qingdao port. Some experiences about potential plan within the port development will be presented, followed by suggestions for other port sustainability and oceanic strength. The conclusion will come back to the key problem of sustainable port development and innovation, providing the answers to our two questions.

\section{CONCEPTS OF BLUE ECONOMY AND SUSTAINABLE DEVELOPMENT}

To better understand the connection between Blue Economy and sustainable development, it is necessary to define the two terms and analyse the possibility of integration.

\subsection{The concept of blue economy}

The "Blue Economy" was first discussed for the assessment of the value of the ocean in relation to the development of the marine ecosystem and investments in industry [11] during the 2012 Rio+20 Conference of United Nations Conference on Sustainable Development (UNCSD) [12]. From then on, the concept of Blue Economy has spread throughout the world [1] and has been adopted by different organizations to emphasize the significance of the marine ecosystem, ocean industries, socio-economic growth and so on. The ideas, in fact, are not a wholly new, but a better recognition and usage of the resources and energy of the ocean. Until now, there is not a unified definition of Blue Economy [8], since it can be used in many fields. However, the essential meaning of Blue Economy refers to all beneficial and valuable aspects of long-term ocean development. 


\subsection{The concept of sustainable development}

The well-known definition of "sustainable development" requires that it "meets the needs of the present without compromising the ability of future generations to meet their own needs" [13]. So sustainable development aims a better living, better society, better environment and a better world [14]. With rapid modern development based on economic growth, the needs and desires of humankind are hugely increasing, while resources and energies for global development are limited. In order to obtain a better balance of conflicting goals, promotion of sustainability is considered and practised during economic and social development and governance. From this perspective, sustainable development of the ocean has top priority.

\subsection{Integration of the two concepts}

Blue Economy focuses on oceanic sustainable development based on ocean technology, industries and culture, characterizing the regional economy. According to Meg (2018), Blue Economy is composed of five components: "ecosystem resilience, economic sustainability, community engagement, institutional integration and technical capacity" [8], which are connected with and influencing each other. The relationship between the two concepts is that the idea of the Blue Economy can be seen as a new framework based on sustainable development. It is obvious that a sustainable relationship between land and ocean should be realized and integrated into a socio-economic framework based on continuous capacity-building and innovation. Concluding, "blue economy for sustainable development" has become the number one priority to be promoted [7] as our future depends on our blue world more than on anything else.

\section{OVERVIEW OF THE CHINESE OCEAN ECONOMY}

The Blue Economy can be defined as the marine or ocean economy and its development is subject and aim of the Chinese ocean policy. In order to improve its economic power and trade volume, the Chinese marine industry has been increased for almost three decades relying on coastal ports and cities development. The policy process can be divided into the following stages.

\subsection{The focus and form of the ocean economy}

Since the 1978 reform and opening-up, the Chinese government began to continuously and completely encourage free fishing and transportation as well as adopt many beneficial policy measures for the marine industry [15]. Aiming to promote the marine economy and enhance governance capability, a sustainable development strategy was formally introduced in the marine industry through the China Ocean Agenda 21 in 1996 [2]. Since then, sustainable development and ocean economy were integrated in the economic activities included in the long-term plan. Until 2000, China invested the first 400 billion yuan in the maritime economy. Meanwhile, the average growth rate of the marine economy in China was high at 10.9\% during the Ninth Five-Year Plan period (1996-2000) [10].

In the following ten years, strategic national plans and activities were carried out focusing on the development of the ocean and on ports intensifying global trade and furthering domestic economic growth. In 2006, the Chinese government started the Ocean Economy Accounting System (OEAS) to evaluate the marine benefits and ocean industry, as a quality assessment of the ocean economic statistic data [2]. From then on, the ocean economy was calculated separately from the national economic system. The Gross Ocean Product (GOP) was used for economic evaluation and for the indication of industrial capacity. The proportion 
of GOP in the GDP was simultaneously involved in the components of the economic statistics system and statistic bulletin. During this period, the Chinese ocean economy obtained a rapid growth and made a big contribution to domestic development and global trade, accounting for $9.87 \%$ growth of the GOP in the GDP in 2008 [10].

\subsection{Sustainable development of ocean economy}

If we considering the recent years (2010 to now) with regard to the integrated management and governance of China's marine industry, the transition of the ocean economy for the single purpose of economic benefit and development to a complete national strategic plan and international cooperation is obvious. Simultaneously, the definition and practice of the Blue Economy have been widely adopted for the ecological and environmental protection of the ocean and ports.

On one hand, since the ocean economy development first emerged in the Chinese 12th Five Year Plan" (FYP) (2011-2015) as a top-level strategy, the Chinese government has released plans and documents to improve the sustainability of the ocean power and marine. For example, the Marine Career Development Plan for the 12th FYP has been launched by the state council for the purpose of ocean sustainable development and marine economic efficiency promotion [15]. On the other hand, the Chinese government pay attention to the arrangement of regional economic practices. China has merged 11 major Blue Economy regions along the coast covering the main sea and river provinces [15]. In view of the growing contribution from marine industries to the national GOP, its subdivision was further specified and increased from six sub-sectors in 1996 to 11 in 2014. In the 2005-2014 period the share of the GOP in the national GDP, generated in the Blue Economy regions, grew with more than $9.4 \%$ [16]. At the same time, the Chinese vision on the Blue Economy and oceanic development has begun to focus on proactive and responsible efforts within regional and international cooperation. For example, the 2012 Asia-Pacific Economic Cooperation (APEC) and 2016 Paris Agreement included the Chinese decision on oceanic protection and sustainable development for a long-term and as a top strategy [17]. The primary goal of the Chinese ocean policy can be summarized as the promotion of marine power and blue economic activities [18]. In a word, the Chinese ocean economy has achieved an obvious development and contributed greatly to the national economic strategies. It can be expected that China's economic development will focus more and more on the blue vision.

\section{SUSTAINABLE DEVELOPMENT OF QINGDAO PORT BASED ON THE BLUE ECONOMY FRAMEWORK}

Within the Blue Economy framework, sustainable port development is of utmost importance as ports link the sea or river with inland cities and territories. Successful sustainable port development will make a key contribution to the balance of economic growth, ecological needs and social progress. In fact, the maritime development blueprint has become the main focus of Chinese port management and policies.

As to coastal development in the Blue Economy regions, Shandong province was the first to be mentioned for the status of "Peninsula Blue Economic Zone (BEZ)" in 2011, when "The Development Plan of Shandong Peninsula BEZ" was proposed by the State Council. It was seen as a signal of the national strategy on behalf of blue economic development and proactive oceanic responsibility. Research showed that Shandong Province obtained most fish -6860.746 tons - in China in 2012, contributing the most to the GOP in the area of the Bohai Bay [16], which was also one of the fastest growing container regions by 2015 [19]. Consequently, nine major economic regions and ports in the province were determined to 
improve the marine power and capacity in the fields of manufacturing industry, energy, ecological technology and other ocean-related as well as port-related resources and industries [10], [18].

As the largest port and capital city in Shandong, Qingdao is the leading power of the Blue Economy zone on the Shandong Peninsula [20]. Qingdao is composed of several districts in the city as well as some coastal cities and ports along the Bohai Bay (see Fig. 1). Qingdao port holds the highest position not only in Chinese oceanic development but also when it comes to global economic contribution. The principal goal of this section is to highlight the sustainable development model of Qingdao port, as one of the main new Silk Road ports, as a case of the Blue Economic strategy in China.

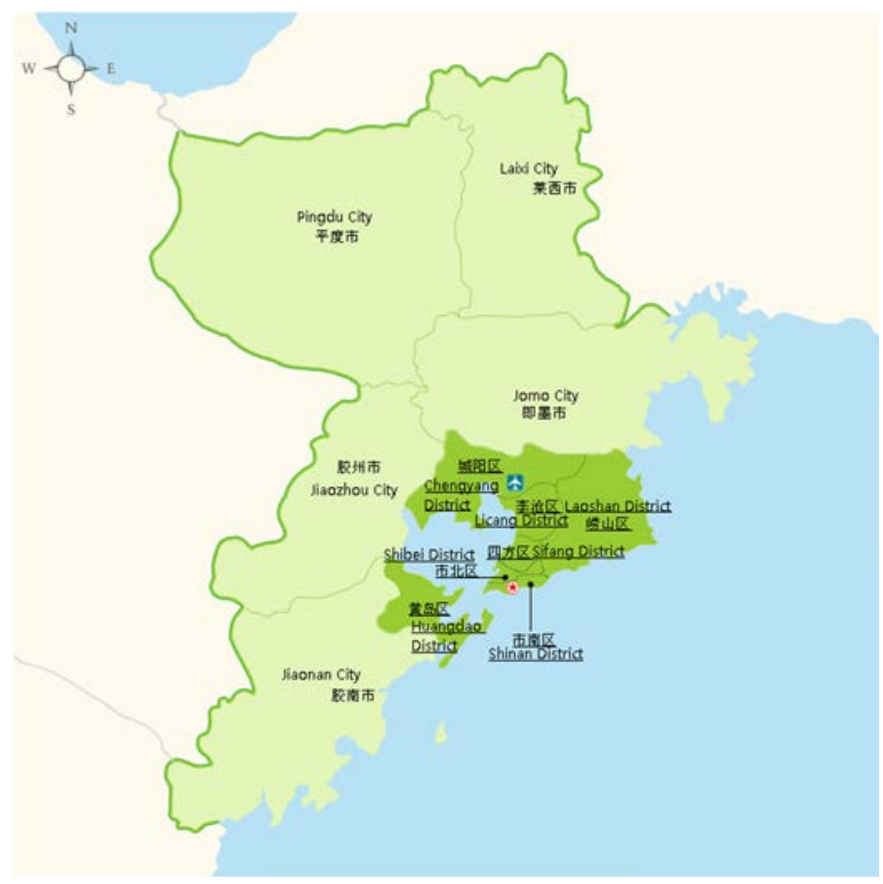

Figure 1: The map of Qingdao city. (Source: Wikimedia Commons, 2009 [32].)

\subsection{Overview of Qingdao port}

The Qingdao port occupies a high and key position in the northern part of East China on the Bohai Bay and Yellow River facing the western Pacific, as one of the largest shipping and container ports of the world, with a long history going back to 1892 when it was built [21]. Nowadays, the port consists of four main port areas: the Dagang Port Area, the Qianwan Port Area, the Huangdao Oil Port Area and the Dongjiakou Port Area (see Fig. 2) [22]. According to statistics, Qingdao port contributed 500 million tons of cargo throughput in 2015, with a growth of $60 \%$ from 2008 to 2014 , and, in that same year, it ranked in the 7th position in the world [19]. Also, covering comprehensive international trade and transportation, it is highly positioned on world port lists for years, including the largest port for inbound crude oil in China and the second largest global trade port for inbound iron ore [21]. Qingdao port was in the top eight of the world container ports, with 9.09 million TEU in the first half of 2017. 


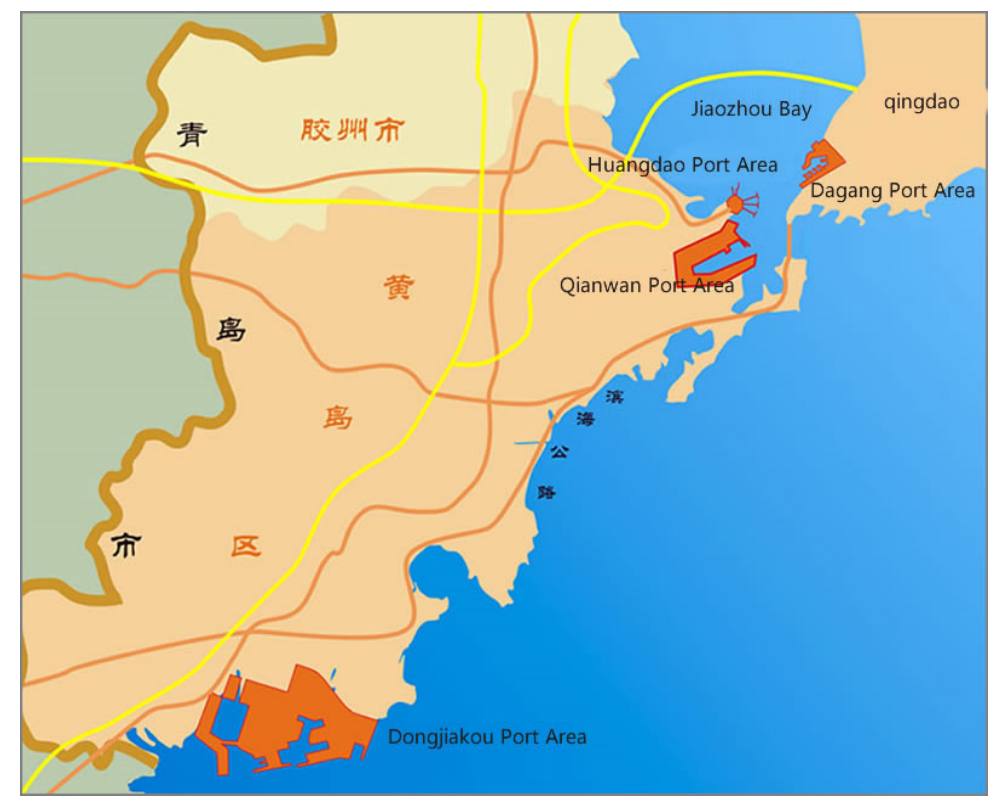

Figure 2: Qingdao port areas. (Source: Qingdao Port International Co., Ltd. [22].)

Since the proposal of the Belt and Road Initiative (BRI) in 2013, Qingdao port has received several labels like the "pivot for strategic ocean cooperation" and the "main node-city in the new Economic Corridor linking Asia and Europe" [20]. According to statistics, Qingdao has invested in total \$US 60 billion into important cooperation projects in the countries along the new Silk Road until 2017, including 11 projects selected by the Chinese national "One Belt, One Road" (OBOR) tank [20]. In the beginning of 2018, there is the global leading load efficiency on the automated terminals of Qingdao port achieving the world record with the average 39.74 unit/machine/hour. It is obvious that Qingdao port is a sustainable port for the future with a strong energy and economic growth potential.

\subsection{Sustainable port development within the Blue Economy method}

The Blue Economy strategy of Qingdao originally began from the proposal of the BEZ in 2011, aimed at leading the sustainable development of oceans and ports and achieving the most socio-ecological coordination. Until now, Qingdao port has obtained a Chinese "green port prize" in 2017 and planned a new development strategy within the framework of the new Silk Road. Under the Chinese new marine strategy, the port of Qingdao, as a typical case of sustainable development, is emerging and moving towards a new trend. According to statistical data, the GOP in Qingdao has reached RMB 290.9 billion in 2017, accounting for 26.4\% of the Qingdao's GDP [23], and with a growth of $15.7 \%$ compared to 2016 (see Fig. 3) [24]. It is clear that ocean-based economic growth has become the significant driver in the regional economic development.

Qingdao port strategy of sustainable development is mainly focusing on the two areas of development under the blue economic method. The first domain of sustainable port development is the construction and improvement of the national core port and "dragon" city under the BRI. Qingdao port and its intercity will become the eastern coastal centre of Blue 


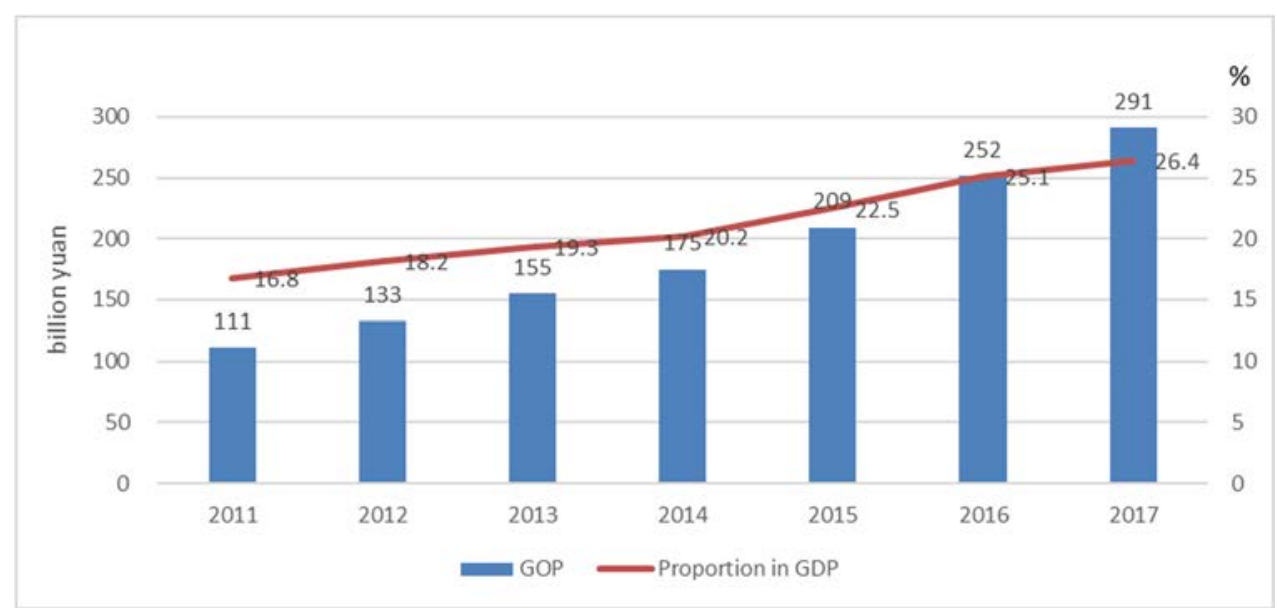

Figure 3: GOP and its proportion in GDP in Qingdao during 2011-2017. (Source: Qingdao Statistic Bulletin 2014-2017 [33], Qingdao Statistic Yearbook 20112017 [34]; graph made by the author.)

Economy, while it will also transition into the leading regional pilot and strategic base for an industrial cluster and high-tech platform [20]. The added value generated by the ocean economy is estimated at 220 billion yuan by 2020 .

The second key development under the Blue economy framework consists of the Qingdao West Coast New Area and the Blue Silicon Valley. The Qingdao West Coast New Area is planned for the purpose of regional cooperation and enlarging maritime economic investment and global trade within the national blue economic framework [25]. The GOP in the New Area of Qingdao has reached the original goals of the planned sustainable enhancement of the port under the Blue Economy, accounting for 86.6 billion yuan of GOP with a share of 21.3\% of Qingdao GDP in 2016 [26]. Another significant initiative is the construction of Blue Silicon Valley (BSV) in Qingdao port. The fascinating global vision centre is a new national initiative under the BEZ located in the eastern part of Jimo to Mount Lao [27] with reference to the famous Silicon Valley in the US. The building of the BSV combined with the New High-Tech Industrial Zone is part of the oceanic strategy and national innovation system in order to highly contribute to the Chinese Blue Economy and the ocean strength dream. The investments and talents in the BSV have continued the efforts for economic growth, environmental protection, oceanic innovation and the new energy transformation. Until now, the $576 \mathrm{~km}^{2}$ area has been constructed in Qingdao port, with an original investment of 55.6 billion yuan and resulting in 200 thousand jobs [25], [27].

\subsection{Qingdao sustainability experience and effect to BRI ports}

As exhibition on the above, the Qingdao sustainable port development has been a leader of the blue ocean strategy with the proactive efforts and continuous construction. According to the research evaluated by $\mathrm{Na}$ et al. [28], in relation to the lowest excessive $\mathrm{CO}_{2}$ emission (almost zero degree) in 2014, Qingdao port has reached the highest PTEE (Pure Technical Environmental Efficiency) among the Chinese container ports [28]. Furthermore, the most significant demonstration of the blue economic strategy is, obviously, located in Qingdao port, taking a leading role for Chinese blue ocean development. 
Synchronously, the activities of Qingdao port sustainability have taken the major responsibilities for the improvements of the ports along the Belt and Road Initiative (BRI). There are 22 friendly cooperation ports which have signed the agreements with Qingdao port for co-management and investment since BRI plan released [29]. In particular, some ports cooperated with Qingdao port corporations have achieved much improvement of the energy conservation and environmental protection. For instance, it is an advantage for Kyaukpyu port in Myanmar that obtained the port environmental improvement, resulted from the cooperation output of Qingdao sustainable port governance [29].

\section{DISCUSSION AND CONCLUSION}

In order to promote the maritime development of the modern Chinese economy, which is considered to be very important, many obvious achievements have been obtained through various governmental plans and their implementation. In this chapter, the Chinese ocean or marine economy has been characterized in terms of the new concept of the "blue economy" and it's being an integral part of China's sustainable development ideals. In addition, a special case has been discussed in order to see how things work out in practice, namely the Qingdao port in the northern part of East China, which is also the showcase of the Chinese government in this respect. In order to emphasize the promotion of the national maritime economy, sustainable development of Qingdao port is focused on under the Blue Economy framework. It is one of the key ports for the blue and ocean visions. Successful practices will be used for further sustainable development initiatives in relation to the Blue Economic Zone strategy. The establishment of some new areas in Qingdao port, for example, has provided opportunities for improvements elsewhere.

However, the challenges should not be neglected. Firstly, the environmental pollution of the ocean is still a key task for the Chinese government to take up. The threat from the deteriorating oceanic habitat and the related disruption of ecological balances will put the port under a large pressure to intensify nature protection. Also, for the coastal areas of Qingdao port, the port's environmental governance capability should still be improved to enable further ocean development.

In addition, Blue Economy is a relatively new concept that has not been put into practice completely. It will take some time to profit from the benefits and value of the new method and the new implied economic pattern. In its implementation, the Chinese government should also consider possible changes with regard to the investments, economic risks, socio-ecological coordination, etc. [30]. This also applies to the BEZ and even to the BRI, as integral aspects of the Blue Economy. Furthermore, new high-tech and innovative methods shall probably increase the efficiency and value for the longer term. The cost of operation, management and monitoring cannot be simply determined without a whole assessment system related to the Blue Economy; such a system should still be developed.

Pending the final sustainable development of an excellent blue ocean port, Qingdao port authorities and stakeholders must implement a number of important steps and activities, supported by additional research. Current efforts, however, focus most on ocean environmental controls on the surface immediately off the coast of the port, while the technical and technical structures for the development and management of deep-sea resources are still lacking. A blue-quality monitoring network for the sustainability objectives of Qingdao port has also not been built yet.

To achieve the practical and theoretical goals, further consideration must be given to dynamic and systematic network research. Moreover, the future research focus could integrate crucial operational indicators of the blue economy and responsible measures for the sustainability of the port, with regard to risks, safety, costs, cooperation and the like. 
To China, the Qingdao port indeed provides a sustainable development model for the coastal regions in their pursuit of Blue Economy aims. The Qingdao port could also be a good reference case for future oceanic strategies developed in connection with the 21 st-century Maritime Silk Road, both in China and abroad [31].

\section{ACKNOWLEDGEMENTS}

The research for this paper has been supported by the China Scholarship Council (CSC NO. 201707167030). It was part of the "The Tao of Responsible Port Innovation" project at Delft University of Technology, the Humanities and Social Sciences Project of Harbin Normal University (SXP2014-07) as well as the Heilongjiang Philosophy and Social Sciences Plan Project (16JYC05).

\section{REFERENCES}

[1] Bari, A., Our oceans and the blue economy: Opportunities and challenges. Procedia Engineering, 194, pp. 5-11, 2017.

[2] Zhao, R., Hynes, S. \& He, G.S., Defining and quantifying China's ocean economy. Marine Policy, 43, pp. 164-173, 2014.

[3] Cheng, W., Zhang, Y. \& Yin, B., On coordinated development of industrial clusters in maritime economy. China Opening Journal, 2, pp. 82-85, 2015. (In Chinese.)

[4] Vision and Actions on Jointly Building Silk Road Economic Belt and 21st-Century Maritime Silk Road; National Development and Reform Commission (NDRC), Ministry of Foreign Affairs, Ministry of Commerce of the People's Republic of China. http://en.ndrc.gov.cn/newsrelease/201503/t20150330_669367.html. Accessed on: 3 Aug. 2015.

[5] Vision for Maritime Cooperation under the Belt and Road Initiative; National Development and Reform Commission (NDRC), the State Oceanic Administration (SOA). https://eng.yidaiyilu.gov.cn/zchj/qwfb/16639.htm. Accessed on: 20 Jun. 2017.

[6] Chen, M. \& Han, L., Driving factors, areas of cooperation and mechanisms for international cooperation in the blue economy of the 21 st-century maritime Silk Road. Engineering Sciences, 18(2), pp. 98-104, 2016. (In Chinese.)

[7] Kathijotes, N., Keynote: Blue economy-environmental and behavioural aspects towards sustainable coastal development. Procedia-Social and Behavioral Sciences, 101, pp. 7-13, 2013.

[8] Keen, M.R., Schwarz, A.M. \& Wini Simeon, L., Towards defining the Blue Economy: Practical lessons from pacific ocean governance. Marine Policy, 88, pp. 333-341, 2018.

[9] Sislian, L., Jaegler, A. \& Cariou, P., A literature review on port sustainability and ocean's carrier network problem. Research in Transportation Business \& Management, 19, pp. 19-26, 2016.

[10] Ding, J., Ge, X. \& Casey, R., "Blue competition" in China: Current situation and challenges. Marine Policy, 44, pp. 351-359, 2014.

[11] Mulazzani, L. \& Malorgio, G., Blue growth and ecosystem services. Marine Policy, 85, pp. 17-24, 2017.

[12] Blue Economy Concept Paper; United Nations, 2014 https://wedocs.unep.org/bitstream/handle/20.500.11822/11129/unep_swio_sm1_inf1 1 blue economy.pdf?amp $\% 3$ BisAllowed $=\&$ sequence $=1$.

[13] Keeble, B.R., The Brundtland report: 'Our common future'. Medicine and War, 4(1), pp. 17-25, 1988. 
[14] Ravesteijn, W., He, J. \& Chen, C., Responsible innovation and stakeholder management in infrastructures: The Nansha Port Railway Project. Ocean \& Coastal Management, 100, pp. 1-9, 2014.

[15] Jiang, X., Liu, T. \& Su, C., China's marine economy and regional development. Marine Policy, 50, pp. 227-237, 2014.

[16] Yan, X., Yan, L., Yao, X. \& Liao, M., The marine industrial competitiveness of blue economic regions in China. Marine Policy, 62, pp. 153-160, 2015.

[17] Zhang, Y. \& Ravesteijn, W., Opening up to the world: Chinese foreign policies as a framework for indigenous development along the new Silk Road. WIT Press Proceedings of Responsible Port Innovation and Sustainable Development along the 21st Century Maritime Silk Road, 2019.

[18] Workshop on US and Chinese Perspectives on the Blue Economy; CMSI Bulletin 2. https://dnnlgwick.blob.core.windows.net/portals/0/NWCDepartments/China\%20Mari time\%20Studies\%20Institute/CMSI-Bulletin-OCT-2015.pdf?sr=b\&si=DNNFile ManagerPolicy\&sig=4ixb2uLGzbN5oA61umcu7Vmb4gVdpPlK5v2kizAnZp4\%3D.

[19] Notteboom, T. \& Yang, Z., Port governance in China since 2004: Institutional layering and the growing impact of broader policies. Research in Transportation Business \& Management, 22, pp. 184-200, 2017.

[20] As the blue economic zone rencounters the "Belt and Road Initiative", the core Qingdao will face great changes; Ifeng.com. http:/qd.ifeng.com/a/20170223/ 5412279 0.shtml. Accessed on: 23 Feb. 2017. (In Chinese.)

[21] Chinadaily, Introduction to the Port of Qingdao. http://qingdao.chinadaily.com.cn/ 2010-02/24/content_9497992.htm. Accessed on: 24 Feb. 2010.

[22] Qingdao Port International Co. Ltd., www.qingdao-port.com/en/gywm_gsjj.jsp.

[23] Xinhuanet, The motivation of "blue economy" in Qingdao was enhanced. www.xinhuanet.com/2018-03/31/c_1122620045.htm. Accessed on: 31 Mar. 2018. (In Chinese.)

[24] Qingdao Bureau of Statistics, The development overview of the ocean economy of Qingdao in 2016. http://qdtj.qingdao.gov.cn/n28356045/n32561934/n32561948/ 180324172006370441.html. Accessed on: 9 Mar. 2017. (In Chinese.)

[25] Chinabriefing, Qingdao's Blue Economy: Marine Investment on the Rise. www.chinabriefing.com/news/qingdaos-blue-economy-marine-investment-rise/. Accessed on: 12 Jun. 2014.

[26] Qingdaonews, Blue economy in Qingdao West Coast will be 165 billion yuan in 2020. http://news.qingdaonews.com/qingdao/2017-06/08/content_12069614.htm. Accessed on: 8 Jun. 2017. (In Chinese.)

[27] That's Qingdao, Qingdao Blue Silicon Valley (Oceantec Valley). www.thatsqingdao.com/qingdao-blue-economic-zone/. (In Chinese.)

[28] Na, J.-H., Choi, A.-Y., Ji, J. \& Zhang, D., Environmental efficiency analysis of Chinese container ports with $\mathrm{CO}_{2}$ emissions: An inseparable input-output SBM model. Journal of Transport Geography, 65, pp. 13-24, 2017.

[29] Ship News, The international route of Chinese ports along "One Belt, One Road", 2018. www.ship.sh/news_detail.php?nid=31101. (In Chinese.)

[30] Choi, Y.R., The Blue Economy as governmentality and the making of new spatial rationalities. Dialogues in Human Geography, 7(1), pp. 37-41, 2017.

[31] Duchâtel, M. \& Sheldon Duplaix, A., Blue China: Navigating the Maritime Silk Road to Europe, Policy Brief, 23rd April, 2018. www.ecfr.eu/publications/summary/ blue_china_navigating_the_maritime_silk_road_to_europe. Accessed on: 4 Oct. 2018. 
[32] Wikimedia Commons, 2009. https://commons.wikimedia.org/wiki/File:Qingdao_AMap.gif\#filehistory.

[33] Qingdao Bureau of Statistics, Qingdao Statistical Bulletin (2014-2017). http://qdtj.qingdao.gov.cn/n28356045/n32561056/n32561072/index.html. (In Chinese.)

[34] Qingdao Bureau of Statistics, Qingdao Statistical Yearbook (2011-2017). www.stats-qd.gov.cn/n28356045/n32561056/n32561073/index.html. (In Chinese.) 